\title{
Status and perspectives of hospital mortality in a public urban Hellenic hospital, based on a five-year review
} Iordanis N Papadopoulos*1, Maria Papaefthymiou ${ }^{1}$, Leonidas Roumeliotis ${ }^{1}$, Vasilios G Panagopoulos ${ }^{2}$, Anna Stefanidou ${ }^{3}$ and Anastasia Kostaki ${ }^{3}$

Address: ${ }^{1}$ National University of Athens, 'Attikon' University General Hospital, Fourth Surgery Department, 1 Rimini Street, 124 62, Athens, Greece, ${ }^{2}$ Department of Medical Informatics, General Hospital of Nikaias Piraeus, 3 Maduvalou Street, 18454 Nikaias, Piraeus, Greece and ${ }^{3}$ Athens University of Economics and Business, Department of Statistics, 76 Patission Avenue, 10434 Athens, Greece

Email: Iordanis N Papadopoulos* - ipapado@med.uoa.gr; Maria Papaefthymiou - marypapdoc@yahoo.com;

Leonidas Roumeliotis - leonidasroumeliotis@yahoo.gr; Vasilios G Panagopoulos - vpan@nikaia-hosp.gr; Anna Stefanidou - astef@otenet.gr; Anastasia Kostaki - kostaki@aueb.gr

* Corresponding author

Published: 23 January 2008

BMC Public Health 2008, 8:28 doi:10.1 I86/147|-2458-8-28
Received: 2I July 2007

Accepted: 23 January 2008

This article is available from: http://www.biomedcentral.com/147I-2458/8/28

(c) 2008 Papadopoulos et al; licensee BioMed Central Ltd.

This is an Open Access article distributed under the terms of the Creative Commons Attribution License (http://creativecommons.org/licenses/by/2.0), which permits unrestricted use, distribution, and reproduction in any medium, provided the original work is properly cited.

\section{Abstract}

Background: Analysis of hospital mortality helps to assess the standards of health-care delivery.

Methods: This is a retrospective cohort study evaluating the causes of deaths which occurred during the years 1995-1999 in a single hospital. The causes of death were classified according to the International Statistical Classification of Diseases (ICD- I0).

Results: Of the 149,896 patients who were discharged the 5836 (3.4\%) died. Males constituted 55\% and females $45 \%$. The median age was 75.1 years (I day - 100 years).

The seven most common ICD-I0 chapters IX, II, IV, XI, XX, X, XIV included $92 \%$ of the total 5836 deaths.

The most common contributors of non-neoplasmatic causes of death were cerebrovascular diseases (160-169) at I5.8\%, ischemic heart disease (120-125) at 10.3\%, cardiac failure (150.0-150.9) at 7.9\%, diseases of the digestive system (K00-K93) at $6.7 \%$, diabetes mellitus (EIO-EI4) at 6.6\%, external causes of morbidity and mortality (V0I-Y98) at 6.2\%, renal failure (NI7$\mathrm{NI9})$ at $4.5 \%$, influenza and pneumonia (J10-JI8) at $4.1 \%$ and certain infectious and parasitic diseases (A00-B99) at 3.2\%, accounting for $65.3 \%$ of the total 5836 deaths.

Neoplasms (C00-D48) caused $17.7 \%(n=1027)$ of the total 5836 deaths, with leading forms being the malignant neoplasms of bronchus and lung $(\mathrm{C} 34)$ at 3.5\% and the malignant neoplasms of large intestine (CI8-2I.2) at I.5\%. The highest death rates occurred in the intensive care unit (23.3\%), general medicine (10.7\%), cardiology $(6.5 \%)$ and nephrology $(5.5 \%)$.

Key problems related to certification of death were identified. Nearly half of the deaths $(49.3 \%: n=2879)$ occurred by the completion of the third day, which indicates the time limits for investigation and treatment. On the other hand, $6 \%(n=356)$ died between the $29^{\text {th }}$ and $262^{\text {nd }}$ days after admission.

Inadequacies of the emergency care service, infection control, medical oncology, rehabilitation, chronic and terminal care facilities, as well as lack of regional targets for reducing mortality related to diabetes, recruitment of organ donors, provision for the aging population and lack of prevention programs were substantiated.

Conclusion: Several important issues were raised. Disease specific characteristics, as well as functional and infrastructural inadequacies were identified and provided evidence for defining priorities and strategies for improving the standards of care. Effective transformation can promise better prospects. 


\section{Background}

Health care demands are rapidly expanding in Greece and upgrading of the health care system is a pressing need. Priorities for transformation are not always easy to define and should be based on evidence. Analysis of hospital mortality can help to assess the standards of health care delivery. Within this context this study investigated the mortality in a single urban, public hospital, the General Hospital of Nikaias Piraeus. The hospital accommodates 750 beds and accepts patients for acute and elective, secondary and tertiary, medical and surgical care. The hospital belongs to the Third Regional Health and Welfare System of Greater Athens, which serves a population of approximately 1,500,000 and is constituted by eight national hospitals, five health care centers, and fourteen regional infirmaries. These offer in total approximately 4,200 available beds and employ approximately 7,500 professionals of various specializations [1].

\section{Methods}

\section{Aims, design and settings}

The objectives of this retrospective cohort study were to substantiate the status and to identify disease-specific, functional and infrastructural factors associated with the hospital mortality, in order to produce evidence for upgrading health care.

For this purpose, the causes of the in-hospital deaths among those who were treated and discharged from the General Hospital of Nikaias Piraeus, during the five years starting on 1 January 1995 and ending on 31 December 1999 were evaluated.

In Greece, there is a legal obligation for a medical professional to certify death, to complete the international form of death certificate, which is recommended by the World Health Organization (WHO) [2], and to refer the deceased for autopsy and death certification when the cause of death is not clear.

\section{Data source and measurements}

The data of this study were extracted from the electronic database of the hospital and included demographics, medical specialty involved in the care of the patients, dates of admission and discharge and the causes and dates of deaths as were recorded in the electronic and un-coded forms of death certificates.

The causes of death were coded according to the International Statistical Classification of Diseases and related health problems, $10^{\text {th }}$ Revision (ICD-10) [3]. When more than one cause of death was stated in Part I of the death certificate, the proper sequence of the underlying causes was selected. The underlying cause of death was taken as defined in the ICD-10, i.e. the disease or injury that initi- ated the train of morbid events leading directly to death, or the circumstances of the accident or violence that produced the fatal injury.

Death certificates were a source of structured data available in electronic form. However, focusing and classifying deaths by the underlying cause results in the underestimation of diseases that are extremely important for assessing the workload and the status of the hospital care when the intention is to produce evidence for upgrading health care. For this reason additional analyses with respect to relative frequencies of common diseases for which the patients were actually treated in the hospital such as, diabetes mellitus, hypertensive diseases, cardiac failure, renal failure, acute tubulo-interstitial nephritis, influenza and pneumonia as well as sepsis, septicemia and septic shock were performed.

In order to evaluate consistency in coding, the first three authors worked together in coding the first 100 death certificates. Consequently, the second and third authors classified all the causes of death independently and the intrarater variation was tested.

\section{Statistics}

Kappa statistics were used to identify consistency between the two coders [4]. All statistical analyses were performed using the Statistical Package for the Social Sciences version $10^{\text {th }}$ (SPSS, Chicago, Illinois, USA). The ethics committee of the General Hospital of Nikaias Piraeus, Greece, has approved this study.

\section{Results \\ Sample size}

Over the five-year period studied, 5836 patients of those who were admitted in this hospital died. The deceased represent $3.4 \%$ of the 149,896 patients who were discharged from the hospital and $1.9 \%$ of the 303,366 who had a planned outpatient consultation.

During the same period 850,000 patients had a consultation in the accident and emergency department. The sample size of the study represents $1.15 \%$ of all the 506,608 deaths that occurred throughout Greece during the same time and are reported by the National Statistics Service.

\section{Gender and age}

Males constituted 55\% $(\mathrm{n}=3208)$ and females $45 \%(\mathrm{n}=$ 2628 ) of the total 5836 deceased. The median age for males and females was 75.1 years (ranged: less than 1 day to 100 years), but 73.1 (ranged: less than 1 day to 99 years) for the male and 77.3 (ranged: less than 1 day to 100 years) for the female subsets. 
As to the ages at death, $3725(63.7 \%)$ of the deceased were over 70 years old, while $1000(17.1 \%)$ of the deceased were 85 years or older. The gender and age distribution are shown in Table 1.

\section{Death rates per medical specialty}

A subset of 2775 (47.5\% of the total 5836) deaths occurred while the patients were under the care of general medicine physicians, 1148 (19.7\%) under cardiologists, $496(8.5 \%)$ under general surgeons and 384 (6.6\%) under neurosurgeons, accounting for $4803(82.3 \%)$ of the total 5836 deaths. The highest death rates (deaths over discharged from specializing unit) occurred in the intensive care unit (23.3\%), the general medicine (10.7\%), cardiology $(6.5 \%)$ and nephrology (5.5\%). The distribution of death rates per specialty is shown in Table 2.

\section{Hospitalization time}

The median hospitalization time was three days (ranged from less than 24 hours to 262 days) and $75 \%$ and $95 \%$ of the deaths occurred by the $9^{\text {th }}$ and $31^{\text {st }}$ days from admission, respectively. On the other hand, $6 \%(n=365)$ died in the hospital between 29 and 262 days from admission. The distribution of deaths from the time of admission is shown in Table 3.

\section{Consistency in coding the causes of death}

A high consistency was found between the two coders in coding the causes of death, with 5526 of the 5836 receiving identical codes $(\mathrm{k}=0.943, \mathrm{p}=0.003)$. A subset of 310 deaths initially classified in different chapters by the two authors. The most common differences between the two coders observed in the following blocks: A00-B99, certain infectious and parasitic diseases ( $\mathrm{n}=14,0.3 \%)$; C00D48, neoplasms: all codes $(\mathrm{n}=15,0.4 \%)$; C00-D48, neoplasms (all codes except the following specified) $(\mathrm{n}=12$, $0.2 \%$ ); E00-E90, endocrine, nutritional and metabolic diseases: all codes $(n=10,0.2 \%)$; E10-E14, diabetes mellitus ( $\mathrm{n}=11,0.2 \%$ ); I00-I99, diseases of the circulatory system (all codes except the following specified) $(\mathrm{n}=14$, $0.3 \%)$; I50.0-I50.9, cardiac failure ( $\mathrm{n}=11,0.2 \%)$; J00J99, diseases of the respiratory system: all codes $(n=27$, 0.4 ); J10-J18, influenza and pneumonia ( $\mathrm{n}=17,0.3 \%)$; K00-K93, diseases of the digestive system $(n=17,0.3 \%)$; V01-Y98, external causes of morbidity and mortality: all codes $(n=17,0.3 \%)$. Consequently the 310 deaths were reviewed by the three first authors, consensus was achieved and the resulted classification was further analyzed.

\section{Relative frequencies of common causes of death}

The following seven most common ICD-10 chapters IX (Diseases of the circulatory system: all codes), II (Neoplasms: all codes), IV (Endocrine, nutritional and metabolic diseases: all codes), XI (Diseases of the digestive system), XX (External causes of morbidity and mortality: all codes), $X$ (Diseases of the respiratory system: all codes), and XIV (Diseases of the genitourinary system: all codes $)$ included $92 \%(n=5369)$ of the total 5836 deaths and are shown in Table 4.

Table I: Gender and age distributions of the 5836 deceased.

\begin{tabular}{|c|c|c|c|c|}
\hline Age groups & Males and females, $\mathrm{n}$ & Males and females, \% & Males, $\mathrm{n}$ & Females, $\mathrm{n}$ \\
\hline $0-4$ & 84 & $\mathrm{I} .4$ & 47 & 37 \\
\hline $5-9$ & 2 & 0.0 & I & I \\
\hline $10-14$ & 3 & 0.1 & 2 & I \\
\hline $15-19$ & 16 & 0.3 & 12 & 4 \\
\hline $20-24$ & 34 & 0.6 & 26 & 8 \\
\hline $25-29$ & 40 & 0.7 & 23 & 17 \\
\hline $30-34$ & 36 & 0.6 & 20 & 16 \\
\hline $35-39$ & 54 & 0.9 & 37 & 17 \\
\hline $40-44$ & 67 & 1.1 & 41 & 26 \\
\hline $45-49$ & 116 & 2.0 & 78 & 38 \\
\hline $50-54$ & 175 & 3.0 & 129 & 46 \\
\hline $55-59$ & 181 & 3.1 & 114 & 67 \\
\hline $60-64$ & $4 \mid 4$ & 7.1 & 264 & 150 \\
\hline $65-69$ & 663 & 11.4 & 425 & 238 \\
\hline $70-74$ & 884 & $15 . \mid$ & 499 & 385 \\
\hline $74-79$ & 900 & 15.4 & 484 & 416 \\
\hline $80-84$ & 941 & 16.1 & 453 & 488 \\
\hline$>85$ & 1000 & 17.1 & 430 & 570 \\
\hline Known age & 5610 & 96.1 & 3085 & 2525 \\
\hline Missing data & 226 & 3.9 & 123 & 103 \\
\hline Total & 5836 & 100 & 3208 & 2628 \\
\hline
\end{tabular}


Table 2: Distribution of death rates per specialty.

\begin{tabular}{lccc}
\hline Specialty & Deaths, $\mathrm{n}$ & \% of deaths & Discharged patients, (All years) \\
\hline General medicine & 2775 & 47,5 & 25975 \\
Cardiology & 1148 & 19,7 & 17697 \\
General surgery & 496 & 8,5 & 16413 \\
Neurosurgery & 384 & 6,6 & 8759 \\
Chest physicians & 218 & 3,7 & 4318 \\
Nephrology & 192 & 3,3 & 3494 \\
Orthopedics & 153 & 2,6 & 7368 \\
Intensive care unit & 120 & 2,1 & 514 \\
Neurology & 87 & 1,5 & 4438 \\
Neonatology & 80 & 1,4 & 1507 \\
Urology & 64 & 1,1 & 10141 \\
Thoracic surgery & 55 & 0,9 & 1841 \\
Remaining specialties & 51 & 0,9 & $4743 \mid$ \\
Unknown & 13 & 0,2 & 149,896 \\
Total & 5,836 & 100 &
\end{tabular}

\section{Non-neoplasmatic causes of death}

The most common contributors of non-neoplasmatic causes of death were cerebrovascular diseases (I60-I69) at $15.8 \%$, ischemic heart disease (I20-I25) at 10.3\%, cardiac failure (I50.0-I50.9) at 7.9\%, diseases of the digestive system (K00-K93) at 6.7\%, diabetes mellitus (E10-E14) at $6.6 \%$, external causes of morbidity and mortality (V01Y98) at $6.2 \%$, renal failure (N17-N19) at $4.5 \%$, influenza and pneumonia (J10-J18) at $4.1 \%$ and certain infectious and parasitic diseases (A00-B99) at 3.2\%. These most common causes together accounted for $65.3 \%$ of the total 5836 deaths.

\section{Common diseases within the ICD-I0 chapters}

With respect to the relative frequencies of common diseases within the ICD-10 chapters, the following was revealed. Sepsis, septicemia or septic shock (non-distinguishably used) was the most commonly reported cause of death of the 185 patients classified in certain infectious and parasitic diseases (A00-B99), accounting for $66.4 \%$ $(\mathrm{n}=123)$. Influenza and pneumonia $(\mathrm{J} 10-\mathrm{J} 18)$ caused $69 \%(\mathrm{n}=240)$ of the 348 deaths due to diseases of the respiratory system (J00-J99). Renal failure (N17-N19) was the commonest cause of death, with $76.5 \%(\mathrm{n}=261)$, and acute tubulo-interstitial nephritis (N10-N16) the second most common cause of death, with $19.6 \%(n=67)$, of the total of 341 deaths attributed to diseases of the genitourinary system (N00-N99). Of the 437 deaths classified in the 'endocrine, nutritional and metabolic diseases' (E00E90), diabetes mellitus (E10-E14) caused $87.8 \%$ ( $\mathrm{n}=$ 384). Coding diabetes mellitus (E10-E14) as underlying cause of death included 76 patients who were treated with cardiac failure and 45 patients treated with renal failure. Coding hypertensive diseases (I10-I15) as underlying cause of death also included 18 patients treated for cardiac failure and 1 patient treated for renal failure. Hence, the

Table 3: The distribution of deaths from the time of admission.

\begin{tabular}{lccc}
\hline Day & Frequency, $\mathrm{n}$ & Per cent* & Cumulative percentage \\
\hline$<1$ & 811 & 13,9 & 13,9 \\
1 & 1039 & 17,8 & 31,7 \\
2 & 574 & 9,8 & 41,5 \\
3 & 455 & 7,8 & 49,3 \\
4 & 359 & 6,2 & 55,5 \\
5 & 307 & 5,3 & 60,8 \\
6 & 234 & 4 & 64,8 \\
7 & 224 & 3,8 & 68,6 \\
2 nd week & 962 & 16,5 & 85,1 \\
3 rd week & 328 & 5,5 & 90,7 \\
4 th week & 186 & 3,2 & 93,9 \\
Day 29 to 262 & 356 & 6 & 100 \\
Total & 5835 & & \\
Missing & 1 & & \\
\hline
\end{tabular}

*From day 18 to 31 the percentage ranged from 0.3 to $0.7 \%$. 
Table 4: Classification of the causes of death according to ICD-I0.

\begin{tabular}{|c|c|c|c|c|}
\hline $\begin{array}{l}\text { ICD-10 } \\
\text { Chapter }\end{array}$ & Blocks & ICD-I0 Title & No of deceased & $\begin{array}{c}\text { *Per cent of total } 5836 \\
\text { deceased }\end{array}$ \\
\hline 1 & A00-B99 & Certain infectious and parasitic diseases & 185 & 3.2 \\
\hline \multirow[t]{14}{*}{ II } & C00-D48 & Neoplasms: all codes & 1027 & 17.7 \\
\hline & C00-D48 & $\begin{array}{l}\text { Neoplasms (all codes except the following } \\
\text { specified) }\end{array}$ & 351 & 6.0 \\
\hline & $\mathrm{Cl} 16-16.9$ & Malignant neoplasms of stomach & 62 & 1.1 \\
\hline & $\mathrm{Cl} 8-21.2$ & Malignant neoplasms of large intestine & 88 & 1.5 \\
\hline & $\mathrm{C} 34$ & Malignant neoplasms of bronchus and lungs & 203 & 3.5 \\
\hline & C50 & Malignant neoplasms of the breast & 47 & 0.8 \\
\hline & $\begin{array}{l}\text { C51, C52, C54, C55, } \\
\text { C57, C58 }\end{array}$ & $\begin{array}{l}\text { Malignant neoplasms, female genital organs } \\
\text { (coded) }\end{array}$ & 12 & 0.2 \\
\hline & C53 & Malignant neoplasms of the uterine cervix & 6 & 0.1 \\
\hline & C56 & Malignant neoplasms of the ovary & 17 & 0.3 \\
\hline & $\mathrm{C} 61$ & Malignant neoplasms of the prostate & 33 & 0.6 \\
\hline & C64-68 & Malignant neoplasms of the urinary tract & 74 & 1.3 \\
\hline & C69-72 & $\begin{array}{l}\text { Malignant neoplasms of eye, brain, and other } \\
\text { parts of central nervous system }\end{array}$ & 56 & 1.0 \\
\hline & $\mathrm{C} 8 \mathrm{I}-\mathrm{C} 96$ & $\begin{array}{l}\text { Malignant neoplasms, of the lymphoid, } \\
\text { haemopoietic and related tissue }\end{array}$ & 49 & 0.8 \\
\hline & D46 & Myelodysplastic syndrome & 29 & 0.5 \\
\hline III & D50-D89 & $\begin{array}{l}\text { Diseases of the blood and blood-forming } \\
\text { organs and certain disorders involving the } \\
\text { immune mechanism }\end{array}$ & 42 & 0.7 \\
\hline \multirow[t]{4}{*}{ IV } & E00-E90 & $\begin{array}{l}\text { Endocrine, nutritional and metabolic diseases: } \\
\text { all codes }\end{array}$ & 437 & 7.5 \\
\hline & E00-E90 & $\begin{array}{l}\text { Endocrine, nutritional and metabolic diseases } \\
\text { (all codes except the following specified) }\end{array}$ & 51 & 0.9 \\
\hline & EIO-EI4 & Diabetes mellitus & 384 & 6.6 \\
\hline & E65-E68 & Obesity and other hyperalimentation & 2 & 0.0 \\
\hline $\mathrm{V}$ & F00-F99 & Mental and behavioral disorders & 6 & 0.1 \\
\hline VI & G00-G99 & Diseases of the nervous system & 40 & 0.7 \\
\hline \multirow[t]{7}{*}{ IX } & $100-199$ & Diseases of the circulatory system: all codes & 2461 & 42.1 \\
\hline & $100-199$ & $\begin{array}{l}\text { Diseases of the circulatory system (all codes } \\
\text { except the following specified) }\end{array}$ & 313 & 5.4 \\
\hline & $110-115$ & Hypertensive diseases & 99 & 1.7 \\
\hline & $120-125$ & Ischemic heart diseases & 603 & 10.3 \\
\hline & 146 & Cardiac arrest & 61 & 1.0 \\
\hline & $150.0-150.9$ & Cardiac failure & 462 & 7.9 \\
\hline & $160-169$ & Cerebrovascular diseases & 923 & 15.8 \\
\hline \multirow[t]{5}{*}{$x$} & J00-J99 & Diseases of the respiratory system: all codes & 348 & 6.0 \\
\hline & J00-J99 & $\begin{array}{l}\text { Diseases of the respiratory system (all codes } \\
\text { except the following specified) }\end{array}$ & 21 & 0.4 \\
\hline & رlo-ر18 & Influenza and pneumonia & 240 & 4.1 \\
\hline & $\mathrm{J} 40-\mathrm{J} 47$ & Chronic lower respiratory diseases & 69 & 1.2 \\
\hline & j96 & Respiratory failure not classified elsewhere & 18 & 0.3 \\
\hline $\mathrm{XI}$ & K00-K93 & Diseases of the digestive system & 393 & 6.7 \\
\hline XII & L00-L99 & Diseases of the skin and subcutaneous tissue & 16 & 0.3 \\
\hline XIII & M00-M99 & $\begin{array}{l}\text { Diseases of the musculoskeletal system and } \\
\text { connective tissue }\end{array}$ & 14 & 0.2 \\
\hline
\end{tabular}


Table 4: Classification of the causes of death according to ICD- I0. (Continued)

\begin{tabular}{|c|c|c|c|c|}
\hline \multirow[t]{4}{*}{$\mathrm{XIV}$} & N00-N99 & $\begin{array}{l}\text { Diseases of the genitourinary system: all } \\
\text { codes }\end{array}$ & 341 & 5.8 \\
\hline & N00-N99 & $\begin{array}{l}\text { Diseases of the genitourinary system (all } \\
\text { codes except the following specified) }\end{array}$ & 13 & 0.2 \\
\hline & NIO-N16 & Acute tubulo-interstitial nephritis & 67 & 1.1 \\
\hline & NI7-NI9 & Renal failure & 261 & 4.5 \\
\hline$X \mathrm{VI}$ & P00-P96 & $\begin{array}{l}\text { Certain conditions originating in the perinatal } \\
\text { period }\end{array}$ & 65 & 1.1 \\
\hline$X V I I$ & Q00-Q99 & $\begin{array}{l}\text { Congenital malformations, deformations and } \\
\text { chromosomal abnormalities }\end{array}$ & 18 & 0.3 \\
\hline XVIII & R00-R99 & $\begin{array}{l}\text { Symptoms, signs and abnormal clinical and } \\
\text { laboratory findings, not elsewhere classified }\end{array}$ & 7 & 0.1 \\
\hline \multirow[t]{3}{*}{$x x$} & V0I-Y98 & $\begin{array}{l}\text { External causes of morbidity and mortality: all } \\
\text { codes }\end{array}$ & 362 & 6.2 \\
\hline & $\times 60-X 84$ & Intentional self-harm & 2 & 0.0 \\
\hline & & Not classifiable** & 74 & 1.3 \\
\hline Total & & & 5836 & 100.0 \\
\hline
\end{tabular}

*Per cent of the total 5836 deceased in hospital.

**These deceased were referred for autopsy, the death certificates were issued directly by the forensic medical department and the database of the hospital was not updated.

There were no recorded deaths in the following ICD-I0 blocks; diseases of the eye and adnexa (H00-H59), diseases of the ear and mastoid process (H60-H95), pregnancy, childbirth and the puerperium (O00-099), complications of medical and surgical care (Y40-Y84), factors influencing health status and contact with health services (Z00-Z99) and under the codes for special purposes (U00-U99).

actual workload of patients with cardiac failure was 556 (9.5\% of the total 5836) and the sum of patients with renal failure was $307(5.2 \%$ of the total 5836).

\section{Neoplasms}

Neoplasms (C00-D48) caused 17.7\% ( $\mathrm{n}=1027)$ of the total of 5836 deaths, with leading forms being malignant neoplasms of bronchus and lung (C34) at 3.5\%, malignant neoplasms of the large intestine (C18-21.2) at $1.5 \%$, malignant neoplasms of the urinary tract (C64-68) with $1.3 \%$, malignant neoplasms of the stomach (C16-16.9) with $1.1 \%$, and malignant neoplasms of the breast (C50) with $0.8 \%$. The complete distribution of the causes of death per ICD-10 chapter is shown in Table 4.

\section{Gender in relation to causes of death}

Overall, the deaths of males exceeded the deaths of females by $10 \%$. 'Certain infectious and parasitic diseases' (A00-B99) were 1.2 times more common in males, at a rate $1.8 \%(n=104)$ versus $1.4 \%(n=81)$ in females. Neoplasms (C00-D48) were 1.6 times more common in males, at a rate $10.8 \%(n=633)$ versus $6.8 \%(n=394)$ in females. Malignant neoplasms of bronchus and lungs (C34), of the urinary tract (C64-68) and of the stomach (C16-16.9) were 6, 3.3, and 2.2 times more common in males than in females, respectively. Diseases of the circulatory system (I00-I99) were 1.1 times more common in males, at a rate of $22.5 \%(n=1313)$ versus $19.7 \%(n=$ 1148 ) in females. Diseases of the respiratory system (J00J99) were 1.3 times more common causes of death in males, at a rate $3.4 \%(n=199)$ versus $2.6 \%(n=149)$ in females.

Diseases of the digestive system (K00-K93) were 1.3 times more common in males, at a rate $3.8 \%(n=222)$ versus $2.9 \%(n=171)$ in females. External causes of morbidity and mortality (V01-Y98) were 1.5 times more common causes of death in males, at a rate $3.8 \%(n=227)$ versus $2.4 \%(n=135)$ in females.

A notably increased rate of deaths in females was observed with respect to endocrine, nutritional and metabolic diseases (E00-E90), at a rate $4.3 \%(n=252)$ versus $3.2 \%(n$ $=185)$ and diabetes mellitus (E10-E14) was 1.3 times more common in females.

\section{Age in relation to causes of death}

The most common causes of death for those aged 15-39 years were external causes of morbidity and mortality (V01-Y98). For those aged over 40 years, and throughout the age range, cerebrovascular diseases (I60-I69) was the most common cause of death, and for those aged over 75 years, the rates of cerebrovascular diseases (I60-I69), ischemic heart diseases (I20-I25) and cardiac failure (I50.0-I50.9) were the predominant causes of death. Deaths due to neoplasms (C00-D48) reached the peak of incidence at the ages 65-79, while deaths due to endocrine, nutritional and metabolic diseases (E00-E90) reached their peak at the ages 70-74 years. 


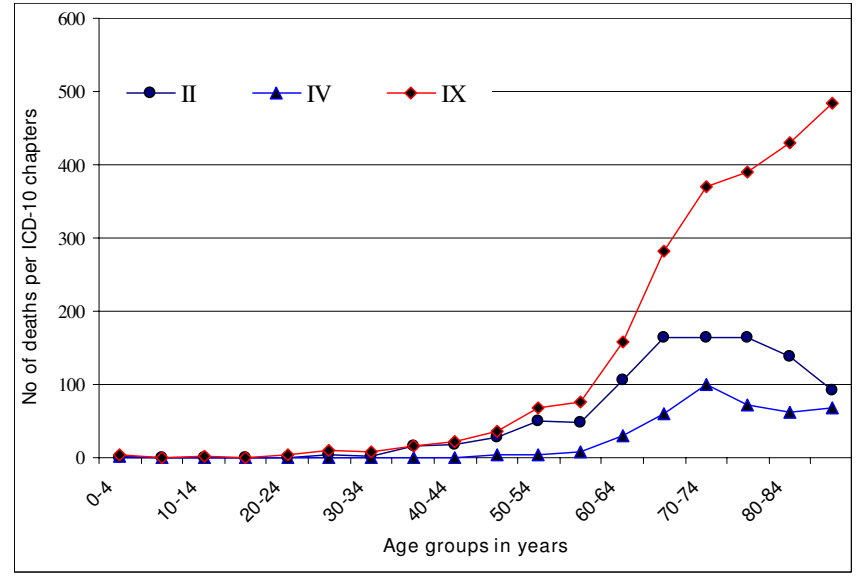

Figure I

Distribution of deaths of the three most common ICD- 10 chapters over the age groups. Distribution of 379 I deaths in the following three chapters; IX: Diseases of the circulatory system (100-199, $\mathrm{n}=2368)$; II: Neoplasms (C00-D48, n = 1004); IV: Endocrine, nutritional and metabolic diseases (E00-E90, $n=419)$.
The distribution of 5175 deaths of the seven most common ICD-10 chapters over the age-groups included (96.3\%) of the total 5369 deaths of these chapters because for the remaining the ages were missing (Figure 1 and Figure 2).

\section{Hospitalization time in relation to gender, age and cause of death}

Before the completion of the first 24 hours after admission, ischemic heart diseases (I20-I25), cerebrovascular diseases (I60-I69) and heart failure (I50-I50.9) were the first, second and third most common causes of deaths, respectively.

Cerebrovascular diseases (I60-I69) were the predominant causes of death in the period from 24 hours until 15 days after admission. Death rates due to ischemic heart diseases (I20-I25) as well as those due to external causes of morbidity and mortality (V01-Y98) reached their peaks before the completion of the first 24 hours.

Neoplasms (C00-D48) were the third most common causes of death from the $8^{\text {th }}$ to the $23^{\text {rd }}$ day, became the first most common cause between the $24^{\text {th }}$ and $30^{\text {th }}$ day, and declined to the second most common cause, following cerebrovascular diseases (I60-I69), after one month.

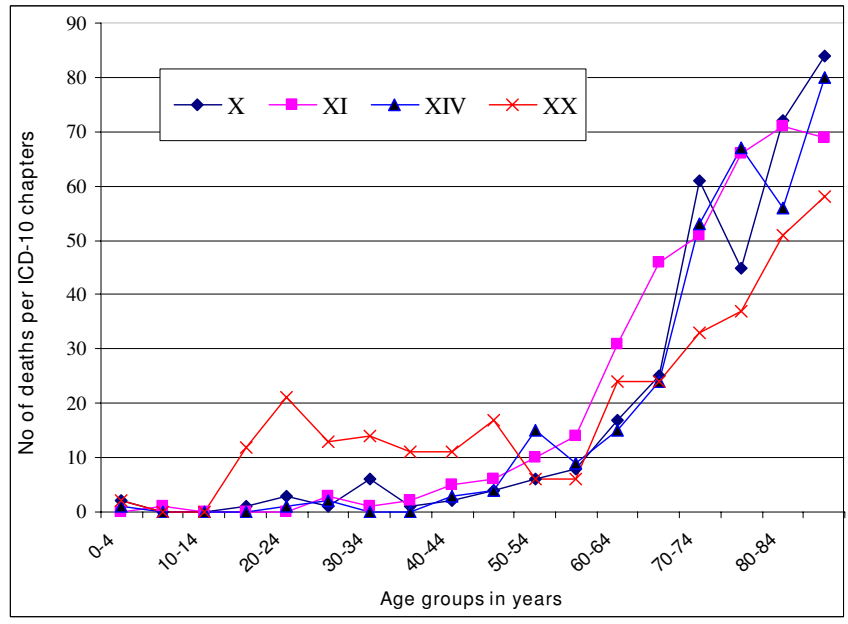

Figure 2

Distribution of deaths of the fourth, fifth, sixth and seventh most common ICD- I 0 chapters, over the age groups. Distribution of 1384 deaths included in the following four chapters; XI: Diseases of the digestive system (K00-K93, $\mathrm{n}=376)$; XX: External causes of morbidity and mortality (V0I-Y98, $\mathrm{n}=340)$; $\mathrm{X}$ : Diseases of the respiratory system (J00-J99, $n=338)$; XIV: Diseases of the genitourinary system (N00-N99, $\mathrm{n}=330)$.

\section{Autopsy rates}

The annual rates of autopsies for those who where admitted and treated in the hospital varied from 7.1 to $9.9 \%$, hence only this proportion of death certificates was based on autopsy findings. The dead on arrival to hospital subjects and those who died in the accident and emergency department before the admission to the wards were not recorded in the electronic database of the hospital and were not further evaluated. Manual research of the archive of 5 years showed that 905 of the 2466 who were dead on arrival or died in the emergency department referred for autopsy and the corresponding annual autopsy rates varied from $34.5 \%$ to $40.8 \%$.

\section{Limitations on data collection}

Proportional hospital mortality was used in this study because access to all hospitals of the country is open to the whole of the population, and estimation of population based data was difficult. In addition, the total 149,896 discharge-diagnoses of this hospital although available in an electronic form they were not coded by the ICD-10. This study was focused on the in-hospital mortality, but the one-month post-discharge mortality rate of those who left the hospital alive was not known.

The date of birth was not recorded in the case of 226 $(3.9 \%)$ of the deceased, and inadequacy of the data pre- 
cluded the classification of the causes of death of 74 $(1.3 \%)$. The latter occurred because the deceased was referred for autopsy, hence the death certificates were issued directly by the forensic medical department but the database of the hospital was not updated. For a total of 61 $(1.0 \%)$ of the deaths, cardiac arrest (I46) was the only recorded diagnosis in Part I and II of the death certificates.

\section{Discussion Problems related to death certification and proposed actions}

This study evaluated the mortality at a single urban hospital which accommodates only $17.8 \%$ of the total beds of this health care region. Completeness of death certificates with respect to date of birth (missing in 3.9\%), and missing data in describing the causes of death (not classifiable for $1.3 \%$ ) could be increased by vigilance in data collection and processing. However, inaccuracies associated with the identification of the causes of death are commonly reported and are related to diagnostic errors [5], to errors in completing the death certificates [6], as well as to errors with respect to the coding process.

In this hospital, the annual autopsy rate (7.1 to $9.9 \%$ ) for those who receive in-hospital care should be increased if it is going to be used for systematic audit, while the high autopsy rate (34.5\% to $40.8 \%$ ) of those who were dead on arrival or died in the accident and emergency department is a subject of further research that may reveal useful information. Substantial improvement of the infrastructure is required to meet the needs of systematic audit by necropsy.

Training, certification of the death by the senior caring physician, and the increasing use of necropsy rates, have been proposed in order to improve the accuracy of data $[6,7]$. Furthermore, the work of international agencies such as WHO [3], EUROSTAT [8], and the National Center for Health Statistics of the USA [9] with the International Collaborative Effort on the consistency, comparability and automation of the cause of death coding systems, should minimize biases in coding and increase the accuracy of mortality data.

In the present study, the absence of recordings with respect to complications of medical and surgical care (Y40-Y84) should be further investigated. Reassurance of the profession from the fear of litigation should yield more accurate data for evaluation of the standards of care.

Currently, coding is centralized by the National Statistics Service but the feedback to the hospital-based clinicians is poor. Trained nosological coders may monitor the mortality, co-ordinate the process of certification and encour- age regular and comparative reviews with the medical records [10].

\section{Gender and age}

National data confirm a general pattern of decreasing mortality rates from 1967 to 1996 [11] and a life expectancy at birth (in 2004) of 77 years for males and 82 years for females [12]. The excess by $10 \%$ of males among the deceased in this study indicates that a larger proportion of females died at home. Males were more prone to suffer the most common causes of death, with the exception of the endocrine, nutritional and metabolic diseases (E00E90).

\section{Causes of death: Can the trends be reversed?}

Proportional hospital mortality which was used in this study has its limitations. Certain infections and parasitic diseases (A00-B99) caused 185 (3.2\%) of the deaths of this study, and sepsis, septicemia and septic shock (nondistinguishably measured) was the most commonly reported cause of death at $66.4 \%(n=123)$. The overall prevalence of hospital-acquired infections reported in 14 out of 112 Greek hospitals was 9.3\% [13], but it is not known for this hospital. The recently established at a national level infection control groups should provide the clinicians with such important data and organize effective surveillance.

Diseases of the circulatory system (I00-I99) caused 2461 $(42.1 \%)$ of the deaths in this study. The reported burden of the total cardiovascular mortality in the European countries represents around $40 \%$ of all-causes mortality for the ages 45-74 years [14]. Cerebrovascular diseases (I60-I69) were the leading causes of death in the present study, with 923 (15.8\%) deceased. The reported 28-day case fatality rate from Greece was 26.6\% [15]. Stroke related mortality has declined in Europe over the period 1970-1996, but not in Greece.

Ischemic heart disease (I20-I25) was the second most common cause of death, accounting for 603 (10.3\%) of the deceased of this study. The age-adjusted mortality due to ischemic heart disease in Greece increased from the 1960 s to the 1990 s $[16,17]$, while it is declining in the USA [18].

In this study, cardiac failure (I50.0-I50.9) caused a high proportion of deaths $(n=462,7.9 \%)$. However, it was observed that the ICD-10 coding underestimated the workload of the hospital with respect to cardiac failure and the actual sum of patients with cardiac failure was 556 (9.5\% of the total 5836). Cardiac failure is a major public health problem with a reported in-hospital mortality of $4 \%$ [19]. 
The findings of the present study indicate that further investigation is required with respect to early diagnosis and the standards of management of the diseases of the circulatory system particularly with respect to cardiac failure, in order to reverse the current trends of mortality.

Neoplasms (C00-D48) caused 1027 deaths (17.7\%) of this study. An increasing trend of mortality due to neoplasms throughout the period 1967-1996 has been recently reported in Greece [11] while the overall number of cancer deaths observed in the European Union recently has reduced by $10 \%$ [20].

Malignant neoplasms of bronchus and lung (C34) was the dominant neoplasm in this study, causing 203 (3.5\%) of the deaths. As has been reported in the United States, lung cancer coded as an underlying cause of death in death certificates captured almost $92 \%$ of all the deceased diagnosed with lung cancer [21].

Malignant neoplasms of the large intestine (C18-21.2) caused $88(1.5 \%)$ of all the deaths in this study, being the second most common cause of deaths due to noeplasms. Malignant neoplasms of the large intestine are reported as the second most common cause of deaths due to neoplasms in Europe also [22]. Malignant neoplasms of the breast (C50) caused $47(0.8 \%)$ of the deaths in this study. The reported age-standardized mortality rate due to breast cancer in Greece is $15.9 \%$ [23]. The risk of dying from breast cancer in the European Union fell by $5 \%$ over the recent years, but an increase of $7 \%$ has been observed in Greece [20].

Malignant neoplasms of the stomach (C16-16.9) caused $62(1.1 \%)$ of the deaths of this study. The risk of dying from gastric cancer in the European Union is declining, but the trend is unknown in this region [20].

Malignant neoplasms of the prostate (C61) caused 33 $(0.6 \%)$ of the deaths of this study. In the European Union, the risk of dying from cancer of the prostate rose by $5 \%$ in 2000 [20].

Despite the fact that approximately one-fifth of the total deaths of the study were due to neoplasms, there are no medical oncology departments in this hospital, and no established screening programs for the asymptomatic population in the region.

Diabetes mellitus (E10-E14) was the underlying cause of $384(6.6 \%)$ deaths in this study. People with diabetes mellitus have a substantially reduced life expectancy, a twofold higher risk of death from cardiovascular disease when compared to non-diabetics [24] and a high risk of developing renal failure. Discrepancies in the coding prac- tice for diabetes mortality have been shown in European countries $[8,25]$.

The data of this study substantiate the need for specification of regional targets for reducing mortality related to diabetes, as has been previously recommended [26].

Diseases of the respiratory system (J00-J99) caused 348 $(6 \%)$ of the deaths of this study. Influenza and pneumonia (J10-J18) caused 240 (4.1\%) of the deaths. Lower respiratory tract infection has been reported recently as the leading cause of mortality among hospitalized patients with hospital-acquired infections in 14 Greek hospitals [27]. The high proportion of deaths attributed to diseases of the genitourinary system (N00-N99) in this study ( $\mathrm{n}=$ 341: $5.8 \%$ ), is due to a large number of patients with chronic renal failure (N17-N19: $\mathrm{n}=261: 4.5 \%)$. This is due to a high volume of patients being treated in a specialized unit of this hospital. An additional number of patients were classified under the codes of diabetes mellitus (E10-E14) and hypertensive diseases (I10-I15) and the actual sum of patients with renal failure was 307 (5.2\% of the total 5836). Effective regional diabetes control prevention programs, as well as increasing the rates of kidney transplantation by recruiting organ donors from trauma-victims offers hope for these patients.

Certain conditions originating in the perinatal period (P00-P96) consisted of $65(1.1 \%)$ of the total deaths, mainly due to premature deliveries. Maternal mortality in Greece has significantly decreased over the last few decades [28].

External causes of morbidity and mortality (V01-Y98) caused $362(6.2 \%)$ of the deaths of the present study and were the most common cause of death for people under 39 years. Preventable trauma deaths and the need for regionalization of trauma care have been substantiated by recent studies from this region $[29,30]$. With respect to mortality associated with natural disasters, potentially preventable deaths from the 1999 Athens earthquake, which affected this region, have recently been reported [31].

Intentional self-harm (X60-X84) is a largely preventable public health problem [32]. The reported suicide mortality rate in Greece over the last decade was approximately 2.8 per $100,000[33,34]$. These low rates have been attributed to the Greek life style, and the characteristic strong family ties. However, the low rate which was observed in this study is misleading, because the deceased are often referred directly to the forensic medical departments for issuing the death certificate and not to the hospitals. Effective prevention is likely to remain elusive, in the absence of adequate data on suicide epidemiology [34]. 


\section{Hospitalization time, acute and chronic care facilities} This study has shown that nearly half ( $\mathrm{n}=2879,49.3 \%$ ) of the total deaths had occurred by the completion of three days from admission, a figure that indicates the time-limits for in-hospital investigation and treatment. Ischemic heart diseases (I20-I25) and external causes of morbidity and mortality (V01-Y98) reached their peaks before the completion of the first 24 hours, hence effective urgent treatment of these groups of patients is vital. On the other hand, $6 \%(n=356)$ of the patients died in the hospital between the $29^{\text {th }}$ and 262nd days after admission, amongst whom cerebrovascular diseases (I60-I69) and neoplasms (C00-D48) were the first and second most common causes of death, respectively. This long time period reflects the lack of rehabilitation as well as lack of chronic health care facilities in the region. While 1000 $(17.1 \%)$ of the deceased were 85 years or older, there are no geriatric wards in this hospital.

\section{Clinical audit}

The essence of this study was to audit health care delivery and despite its limitations it raised and substantiated many relevant and important issues. The apparent high rates of mortality in some specialties, and particularly that of general medicine $(10.7 \%)$, is partly due to the fact that they accommodate many patients for terminal care. The data of this study do not allow further stratification of severity of the diseases. The nature, as well as, the timing of the received therapeutic interventions were unknown, hence further conclusions with respect to standards of care cannot be drawn. Nowadays, it is essential for the medical profession to become the pioneers in establishing regular and effective clinical audit and this study should help in this process.

\section{Study implications, priorities and perspectives}

The problems related to the process of death certification should be promptly resolved. The high volume of admissions and emergency room consultations, in association with the time-limits for investigation and treatment of patients with acute and severe diseases, imply that there is a need for urgent investment and regionalization of the emergency in-hospital care, the pre-hospital emergency medical care and the primary health care sectors of this region.

Infection control, particularly with respect to hospitalacquired infections; the establishment of medical oncology as well as rehabilitation, chronic and terminal health care facilities; regional targets for reducing mortality related to diabetes; recruitment of organ donors and provision for the aging population are some of the issues that need prompt solutions.
Certain well-known risk factors of our lifestyle, such as tobacco [35], and particularly those related to diseases of the circulatory system, to neoplasms and to the respiratory system, are avoidable [15,16]. Public education, trauma prevention, and establishment of screening programs in the region are of vital importance for long term health care benefits. This study shows that there is a place for improving the standards of care, and such effective interventions promise better future perspectives.

\section{Conclusion}

Problems relating to death certification were identified. Monitoring mortality and clinical audit should help to improve the standards of care. Disease specific characteristics were identified and priorities with respect to functional integration and upgrading the infrastructure were suggested. This study should help in planning the reduction of mortality rates. Upgrading of the system promises better prospects in health care delivery and for the longevity of the population of this region.

\section{Competing interests}

The author(s) declare that they have no competing interests.

\section{Authors' contributions \\ Concept and design of the study: INP}

Data extraction and management: VGP, AS, AK

Coding causes of death: MP, LR, INP, VGP

Statistical analysis: AK, AS, INP

Drafting, writing the paper and interpretation: INP, LR, MP.

All authors have read and approved the final version of the manuscript.

\section{References}

I. World Health Organization, Regional Office for Europe. Highlights on health in Greece 2004 [http://www.euro.who.int/ document/chh/gre HIGHLIGHTS.PDF]

2. World Health Organization: Medical Certification of Cause of Death. Instructions for Physicians on Use of International Form of Medical certificate of Cause of Death. Geneva , World Health Organization; 1979.

3. WHO: International statistical classification of diseases and related health problems, I0th Revision, ICD-I0. Edited by: Organization WH. Geneva; 1992.

4. Lang TA SM: Chapter 6. Testing for Relationships. In How to Report Statistics in Medicine Edited by: Physicians AC. Philadelphia, Pennsylvania ; 1995:93-104.

5. Sington JD, Cottrell B]: Analysis of the sensitivity of death certificates in $\mathbf{4 4 0}$ hospital deaths: a comparison with necropsy findings. J Clin Pathol 2002, 55(7):499-502.

6. Swift $B$, West K: Death certification: an audit of practice entering the 2 I st century. J Clin Pathol 2002, 55(4):275-279.

7. Myers KA, Farquhar DR: Improving the accuracy of death certification. Cmaj 1998, 158(10):1317-1323. 
8. Jougla E, Pavillon G, Rossollin F, De Smedt M, Bonte J: Improvement of the quality and comparability of causes-of-death statistics inside the European Community. EUROSTAT Task Force on "causes of death statistics". Rev Epidemiol Sante Publique 1998, 46(6):447-456.

9. Instruction manual part 2c: ICD-I0 ACME decision tables for classifying underlying causes of death. Edited by: Statistics $\mathrm{NCH}$. Hyattsville, MD, US Department of Health and Human Services, Public Health Service; 2001.

10. Curb JD, Babcock C, Pressel S, Tung B, Remington RD, Hawkins CM: Nosological coding of cause of death. Am J Epidemiol 1983, II 8(I): 122-128.

II. Nikolaidis G, Zavras D, Bonikos D, Kyriopoulos J: Trends of mortality rates during the last thirty years in Greece. J Med Syst 2004, 28(6):607-616.

12. World Health Organization: The World Health Report 2006, Greece [http://www.who.int/countries/grc/en/]

13. Gikas A, Pediaditis J, Papadakis JA, Starakis J, Levidiotou S, Nikolaides P, Kioumis G, Maltezos E, Lazanas M, Anevlavis E, Roubelaki M, Tselentis Y: Prevalence study of hospital-acquired infections in 14 Greek hospitals: planning from the local to the national surveillance level. J Hosp Infect 2002, 50(4):269-275.

14. Sans $\mathrm{S}$, Kesteloot $\mathrm{H}$, Kromhout D: The burden of cardiovascular diseases mortality in Europe. Task Force of the European Society of Cardiology on Cardiovascular Mortality and Morbidity Statistics in Europe. Eur Heart J 1997, 18(8): I23I-I 248.

15. Vemmos KN, Bots ML, Tsibouris PK, Zis VP, Grobbee DE, Stranjalis GS, Stamatelopoulos S: Stroke incidence and case fatality in southern Greece: the Arcadia stroke registry. Stroke 1999, 30(2):363-370.

16. Pitsavos C, Panagiotakos DB, Antonoulas A, Zombolos S, Kogias $Y$, Mantas Y, Stravopodis P, Kourlaba G, Stefanadis C: Epidemiology of acute coronary syndromes in a Mediterranean country aims, design and baseline characteristics of the Greek study of acute coronary syndromes (GREECS). BMC Public Health 2005, 5(I):23.

17. Chimonas ET: The treatment of coronary heart disease: an update. Part 2: Mortality trends and main causes of death in the Greek population. Curr Med Res Opin 200I, I 7(I):27-33.

18. Kesteloot H, Sans S, Kromhout D: Evolution of all-causes and cardiovascular mortality in the age-group $75-84$ years in Europe during the period 1970-1996; a comparison with worldwide changes. Eur Heart J 2002, 23(5):384-398.

19. Adams KF Jr., Fonarow GC, Emerman CL, Lejemtel TH, Costanzo MR, Abraham WT, Berkowitz RL, Galvao M, Horton DP: Characteristics and outcomes of patients hospitalized for heart failure in the United States: rationale, design, and preliminary observations from the first 100,000 cases in the Acute Decompensated Heart Failure National Registry (ADHERE). Am Heart J 2005, I49(2):209-2I6.

20. Boyle P, d'Onofrio A, Maisonneuve P, Severi G, Robertson C, Tubiana $M$, Veronesi U: Measuring progress against cancer in Europe: has the 15\% decline targeted for $\mathbf{2 0 0 0}$ come about? Ann Oncol 2003, I 4(8): | $3|2-| 325$.

21. Mannino DM, Ford E, Giovino GA, Thun M: Lung cancer deaths in the United States from 1979 to 1992: an analysis using multiple-cause mortality data. Int J Epidemiol 1998, 27(2): $159-166$.

22. Boyle P, Ferlay J: Cancer incidence and mortality in Europe, 2004. Ann Oncol 2005, I6(3):48I-488.

23. Mettlin C: Global breast cancer mortality statistics. CA Cancer J Clin 1999, 49(3): I38-I44.

24. Gu K, Cowie CC, Harris Ml: Mortality in adults with and without diabetes in a national cohort of the U.S. population, 1971 1993. Diabetes Care 1998, 2 I(7): I | 38-I I 45.

25. Thomason MJ, Biddulph JP, Cull CA, Holman RR: Reporting of diabetes on death certificates using data from the UK Prospective Diabetes Study. Diabet Med 2005, 22(8): 103।-1036.

26. WHO: Diabetes care and research in Europe: the St. Vincent Declaration action programme. 2nd edn. Copenhagen, WHO Regional Office for Europe; 1995.

27. Kofteridis DP, Papadakis JA, Bouros D, Nikolaides P, Kioumis G, Levidiotou S, Maltezos E, Kastanakis S, Kartali S, Gikas A: Nosocomial lower respiratory tract infections: prevalence and risk factors in 14 Greek hospitals. Eur J Clin Microbiol Infect Dis 2004, 23( 12$): 888-89 \mid$.
28. Dimitrakakis C, Papadogiannakis J, Sakelaropoulos G, Papazefkos V, Voulgaris Z, Michalas S: Maternal mortality in Greece (19801996). Eur J Obstet Gynecol Reprod Biol 200I, 99(I):6-13.

29. Papadopoulos IN, Bukis D, Karalas E, Katsaragakis S, Stergiopoulos S, Peros G, Androulakis G: Preventable prehospital trauma deaths in a Hellenic urban health region: an audit of prehospital trauma care. J Trauma 1996, 4I(5):864-869.

30. Papadopoulos IN, Kanakaris N, Bonovas S, Triantafillidis A, Garnavos C, Voros D, Leukidis C: Auditing $\mathbf{6 5 5}$ fatalities with pelvic fractures by autopsy as a basis to evaluate trauma care. J Am Coll Surg 2006, 203(I):30-43.

31. Papadopoulos IN, Kanakaris N, Triantafillidis A, Stefanakos J, Kainourgios A, Leukidis C: Autopsy findings from III deaths in the 1999 Athens earthquake as a basis for auditing the emergency response. $\mathrm{Br}$ J Surg 2004, 9 I ( I 2): 1633-1640.

32. World Health Organization. Suicide huge but preventable public health problem, says WHO [http://www.who.int/media centre/news/releases/2004/pr6I/en/]

33. Vougiouklakis T, Boumba VA, Mitselou A, Peschos D, Gerontopoulos $\mathrm{K}$ : Trends in suicide mortality in the deprived region of Epirus (north-west Greece) during the period 1998-2002. Med Sci Law 2005, 45(I):39-46.

34. Chishti P, Stone DH, Corcoran P, Williamson E, Petridou E: Suicide mortality in the European Union. Eur J Public Health 2003, 13(2): $108-114$.

35. Doll R, Peto R, Wheatley K, Gray R, Sutherland I: Mortality in relation to smoking: $\mathbf{4 0}$ years' observations on male British doctors. Bmj 1994, 309(6959):901-9II.

\section{Pre-publication history}

The pre-publication history for this paper can be accessed here:

http://www.biomedcentral.com/1471-2458/8/28/prepub
Publish with Bio Med Central and every scientist can read your work free of charge

"BioMed Central will be the most significant development for disseminating the results of biomedical research in our lifetime. "

Sir Paul Nurse, Cancer Research UK

Your research papers will be:

- available free of charge to the entire biomedical community

- peer reviewed and published immediately upon acceptance

- cited in PubMed and archived on PubMed Central

- yours - you keep the copyright
BioMedcentral 